\title{
New enzyme-based process direction to prevent wool shrinking without substantial tensile strength loss
}

\author{
H. B. M. Lenting $\cdot$ M. Schroeder • \\ G. M. Guebitz - A. Cavaco-Paulo $\cdot$ J. Shen
}

Received: 17 November 2005/ Accepted: 30 January 2006/Published online: 23 May 2006

(C) Springer Science+Business Media B.V. 2006

\begin{abstract}
In this paper a new enzymatic process direction is described for obtaining machine washable wool with acceptable quality. In general, application of protease enzyme technology in wool processing results in considerable loss of tensile strength by diffusion of the enzyme into the interior of wool fibers. To overcome this disadvantage enzymatic activity has been more targeted to the outer surface of the scales by improving the susceptibility of the outer surface scale protein for proteolytic degradation. This has been realized by a pretreatment of wool with hydrogen peroxide at alkaline $\mathrm{pH}$ in the presence of high concentrations of salt.
\end{abstract}

H. B. M. Lenting ( $\square)$

Department of Innovative Materials, TNO Industry and Technology, Ariënsplein 3, 7511 JX Enschede,

The Netherlands

e-mail: herman.lenting@tno.nl

M. Schroeder · G. M. Guebitz

Department of Environmental Biotechnology,

Graz University of Technology, Graz, Austria

A. Cavaco-Paulo

Department of Textile Engineering,

Minho University, Guimarães, Portugal

J. Shen

Textile Engineering and Materials (TEAM) Research

Group, De Montfort University, Leicester, UK
Keywords Chemical modification - Protease · Surface modification - Wool shrinkage

\section{Introduction}

Wool fabrics in the wet state are sensitive to felt and shrink when applying mechanical action as in the case of washing. It is well known that this felting is caused by tangling of the cuticle surface scales (Cortez et al. 2004). Explanation of this entanglement is the arrangement of the cuticle scales with their outer edges towards the fiber tip. The friction of the wool fiber in the scale direction is therefore lower than the friction against the scale direction, a phenomenon which is called the differential frictional effect. Partial removal of the scales or smoothing the edges from the overlapping scales would reduce mentioned felting tendency. For this purpose, three different processes are commercially practiced: subtractive (oxidation, reduction), additive (synthetic resin layer) and a combined process (e.g. chlorine/ Hercosett process). However, these processes cause environmental concerns (contamination of wastewater with adsorbable organic chlorides) and/or change the natural wool character to a more synthetic handle.

An alternative process is based on enzyme technology. In particular proteases can be used in environmentally friendly processes for partial 
removal of scale cuticles (El-Sayed et al. 2001; Heine and Höcker 1995) or smoothing the edges. A disadvantage of this process is the resulting high level of strength reduction and weight loss (Bishop et al. 1998; Shen et al. 1999). The relative small protease molecules (MW approximately $14-20 \mathrm{kDa}$ for most proteases) are able to penetrate into the fiber and hydrolyze proteins in the cortex cells and cell membrane complex.

Recently it has been suggested that restriction of the enzymatic action towards the wool scale surface would reduce/eliminate the observed internal fiber degradation and subsequent tensile strength loss (Schroeder et al. 2004). The outer surface of the scales are highly cross linked and in practice hardly substrate for proteolytic enzymes. To make enzymatic action effective and to concentrate enzymatic activity on the outer surfaces of scales, the outer scale protein has to be modified prior to enzymatic incubation. Different methods have been examined in the past, showing oxidation of the wool's disulfide bonds as the most effective one. The effectiveness of hydrogen peroxide treatment prior to the enzymatic incubation was shown to give the best results in relation to shrink resistance (Cardamone et al. 2004). However, as a consequence of such treatment the tensile strength was reduced by approximately $70 \%$.

In this paper, application of hydrogen peroxide in combination with salt to target enzymatic activity on the outer surface of the scales in order to obtain shrink resistance with limited impact on tensile strength was investigated.

\section{Experimental}

\section{Materials}

Protex Multiplus L (protease) is kindly donated by Genencor B.V., The Netherlands. Drummond

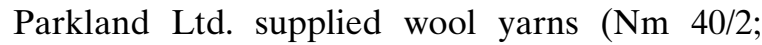
mean diameter 23 microns) which was used to make knitted (Stoll CMS 330; right-right knitting with 2 yarns; 7 needles/inch; stitch 9.5) fabric. All chemicals except Tergitol are of analytical grade.
Hydrogen peroxide pretreatment

Fabrics $(10 \times 10 \mathrm{~cm}, 6 \mathrm{~g})$ and/or yarns on a spool are treated for $30 \mathrm{~min}$ (unless other mentioned) at $55^{\circ} \mathrm{C}$ in the Linitester using $200 \mathrm{ml}$ of $25 \mathrm{mM}$ Tris/HCl buffer containing Tergitol 15-S-12 $(0.5 \mathrm{~g} / \mathrm{l}), 4 \mathrm{~g}$ of a $35 \%$ hydrogen peroxide solution/l (if not specified) and in the presence and absence of $4 \mathrm{M} \mathrm{NaCl}$ at different $\mathrm{pH}$ values. Afterwards the fabric is rinsed twice with an excess of demineralised water.

Enzymatic incubation

Pretreated fabric and/or yarns on a spool are incubated in the Linitester for different time intervals at $55^{\circ} \mathrm{C}$ using $200 \mathrm{ml}$ of $25 \mathrm{mM}$ borax buffer pH 8.5 containing Tergitol 15-S-12 (0.5 g/ 1), $5 \mathrm{mM} \mathrm{CaCl}{ }_{2}$ and Protex Multiplus L protease ( $1 \mathrm{~g}$ enzyme solution/ 1 if not specified). After the incubation the $\mathrm{pH}$ is lowered to 5 and the temperature raised to $75^{\circ} \mathrm{C}$ for subsequent incubation for another $10 \mathrm{~min}$ in order to inactivate the proteolytic enzyme. The fabrics are rinsed, linedried and conditioned for $24 \mathrm{~h}$ at $20^{\circ} \mathrm{C}$ and $65 \%$ Room Humidity prior to evaluation.

Tensile strength loss

Tensile strength of yarn is measured according to ISO 2062 using a Hounsfield tensile tester. The tensile strength is then calculated as percentage of the original sample's tensile strengths.

Shrinkage determination

Shrinkage of fabric is tested according to Woolmark Test Method TM31: the samples were subjected to three wash cycles in a household washing machine, using programme $5 \mathrm{~A}$, and $2 \mathrm{~kg}$ total wash load (polyester fabrics with dimensions of $22 \times 22 \mathrm{~cm}$ ) and standard IEC detergent without bleaching components. Shrinkage is expressed as percentage of remaining surface area.

All experiments are carried out without repetitions but in series wherein a parameter is tested at different values in order to identify tendencies. 


\section{Results and discussion}

It was already shown in 1963 by Bradbury et al. (1963) that use of high concentrations of salt prevents diffusion of agents into the interior of wool fibers. This technique has been combined with the hydrogen peroxide pretreatment at different $\mathrm{pH}$ values, which was followed by enzymatic incubation using different time windows. The results in Table 1 show that peroxide pretreatment has a major impact on all parameters tested under high alkaline circumstances $(\mathrm{pH}$ 11.5). At lower $\mathrm{pH}$ values, the impact of peroxide treatment in combination with enzymatic degradation is marginal in relation to the obtained shrinkage behavior. The peroxide treatment at $\mathrm{pH} 11.5$ alone already resulted in some shrinkage improvement: the remaining surface area improved from 51 to $64 \%$ in the situation with salt addition. The combination of peroxide in the presence of a large quantity of $\mathrm{NaCl}$ followed by subsequent enzymatic treatment resulted in no measurable shrinkage of wool fabric and only moderate weight loss in the largest time window for enzymatic incubation. On the contrary, in the absence of salt, the weight loss was in the same enzymatic incubation time window considerable

Table 1 Shrinkage (after three washings) and weight and tensile strength loss data of knitted wool fabric after $\mathrm{H}_{2} \mathrm{O}_{2}-$ pretreatment at different $\mathrm{pH}$ values in the presence and while the dimensions of the fabric after three subsequent washings cannot be determined due to the formation of holes. It can be concluded that under the conditions tested the enzyme treatment has a severe impact on the integrity of the fabrics when no salt addition had been applied during the peroxide pretreatment. The collected data in the presence of high concentration of salt suggest that the protein modification by peroxide has been concentrated on the fiber surface, resulting in an easy proteolytic degradable surface. Under these circumstances the impact on weight and tensile strength losses are relatively moderate.

These results are in line with those of other authors (Bradbury et al. 1963): with the set of parameters applied no major diffusion of peroxide into the fiber interior, with subsequent severe fiber damage (weight and tensile strength), could be observed. This phenomenon has been explained by the fact that swelling of wool under those circumstances is suppressed (Simpson 2002). Peroxide will therefore modify only protein on the outer surface of wool fibers, creating degradable substrate for proteolytic enzymes. The creation of this easily degradable substrate will also target enzymatic activity more towards this outer surface protein, preventing thus (to a

absence of $4 \mathrm{M} \mathrm{NaCl}$ with subsequent Protex Multiplus L enzyme $(1 \mathrm{~g} / \mathrm{l})$ incubations with different time windows

\begin{tabular}{|c|c|c|c|c|c|c|c|}
\hline \multirow[t]{2}{*}{ Pretreatment $\mathrm{pH}$} & \multirow[t]{2}{*}{ Enzyme time $(\mathrm{min})$} & \multicolumn{2}{|c|}{ Weight loss (\%) } & \multicolumn{2}{|c|}{$\begin{array}{l}\text { Remaining surface area } \\
(\%)\end{array}$} & \multicolumn{2}{|c|}{$\begin{array}{l}\text { Tensile strength loss } \\
(\%)\end{array}$} \\
\hline & & Without salt & With salt & Without salt & With salt & Without salt & With salt \\
\hline \multirow[t]{4}{*}{8.5} & 0 & 0 & 0 & 50.6 & 50.8 & 0 & 0 \\
\hline & 15 & 0.9 & 0.6 & 49.7 & 53.2 & 10.3 & 20.5 \\
\hline & 30 & 1.1 & 1.2 & 52.9 & 53.6 & 15.4 & 5.1 \\
\hline & 45 & 1.4 & 1.2 & 52.3 & 53.8 & 15.4 & 17.9 \\
\hline \multirow[t]{4}{*}{9.5} & 0 & 0 & 0 & 51.3 & 49.7 & 0 & 0 \\
\hline & 15 & 1.1 & 0.8 & 52.3 & 51.6 & 2.9 & 0 \\
\hline & 30 & 1.6 & 1.3 & 54.5 & 52.3 & 0 & 5.7 \\
\hline & 45 & 1.9 & 1.6 & 54 & 50.3 & 0 & 11.4 \\
\hline \multirow[t]{4}{*}{10.5} & 0 & 0 & 0 & 50.7 & 51.3 & 0 & 0 \\
\hline & 15 & 1 & 1.4 & 50 & 52.2 & 13.5 & 0 \\
\hline & 30 & 1.4 & 1.9 & 51 & 54.7 & 2.7 & 15.2 \\
\hline & 45 & 2.1 & 2.9 & 53.5 & 54.9 & 24.3 & 6.1 \\
\hline \multirow[t]{4}{*}{11.5} & 0 & 0 & 0 & 54.4 & 64 & 0 & 0 \\
\hline & 15 & 5.7 & 2.7 & 87.5 & 79.7 & 25 & 17.9 \\
\hline & 30 & 12.5 & 3.3 & 120.8 & 76.7 & 72.2 & 28.2 \\
\hline & 45 & 25.2 & 6.3 & nd & 99.6 & 86.1 & 33.3 \\
\hline
\end{tabular}

nd $=$ not detectable 
certain level) the hydrolysis of protein in the interior of the fibers. As a consequence, this surface modification (smoothening) results in hardly any change in fabric surface area upon repeating washing the fabric while the no enzyme treated fabric shows substantial shrinkage. Peroxide pretreatment in the absence of salt followed by enzyme incubation show substantial enlargement of the fabric during subsequent wash cycles, ending with destructed fabric with holes. This observed fabric enlargement is already a strong indication of severe damage of the internal fiber construction in line with the large tensile strength losses observed (Table 1).

Having shown the potential of hydrogen peroxide in combination with high salt concentration for substantial modification of cross-linked protein on the surface of wool fibers, different parameters of the pretreatment were studied in order to optimize the protein modification process. At first, time was varied up to 60 min using a constant hydrogen peroxide concentration of $4 \mathrm{~g}$ of $35 \%$ solution/l at $\mathrm{pH} 11.5$ in the presence of $4 \mathrm{M} \mathrm{NaCl}$. In the subsequent enzyme incubation the time was varied also up to $90 \mathrm{~min}$. In Fig. 1 the surface area data obtained after three wash cycles are shown for up to $30 \mathrm{~min}$ peroxide pretreatment time. In these experiments it appeared that at the used peroxide concentration a minimum pretreatment time of $30 \mathrm{~min}$ is required to obtain full shrink resistance fabric. The combination of $20 \mathrm{~min}$ pretreatment time or beyond

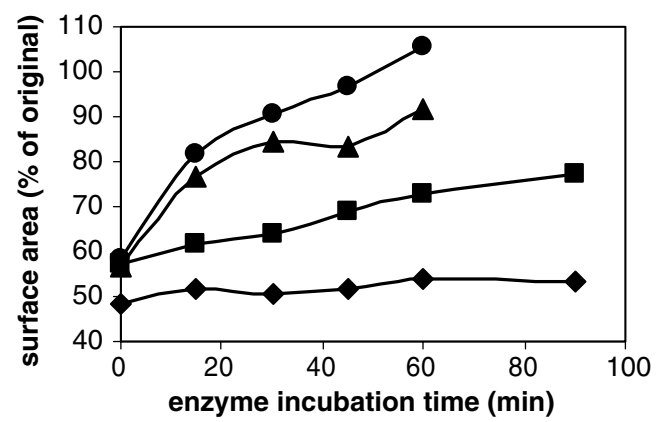

Fig. 1 The impact of varying hydrogen peroxide pretreatment and enzyme incubation times on shrinkage after three wash cycles. The amount of Protex Multiplus L used in the enzyme incubation was $2 \mathrm{~g} / \mathrm{l}$. Abbreviations: $0 \mathrm{~min}, \boldsymbol{\square} 10 \mathrm{~min}, \boldsymbol{\Delta} 20 \mathrm{~min}$ and $30 \mathrm{~min}$ hydrogen peroxide treatment time with 90 min of enzyme incubation resulted in holes in the fabric after the washes and its surface area could not be measured. Tensile strength and weight loss data showed that upon increasing the pretreatment time the weight losses are also increasing while the tensile strength decreases (results not shown). Under the conditions tested, it has been concluded that the pretreatment time should be as short as possible in order to minimize the impact on tensile strength and weight losses of fabric after enzyme incubation.

The second pretreatment parameter investigated is the hydrogen peroxide concentration. A concentration range up to $15 \mathrm{~g}$ of $35 \%$ peroxide solution/l has been tested in a pretreatment for 15 min followed by an enzymatic treatment with Protex Multiplus L in a concentration of $2 \mathrm{~g} / \mathrm{l}$ for different durations. The impact on weight loss after enzymatic incubation and shrinkage after three subsequent washing cycles is shown in Figs. 2 and 3. Increasing the peroxide concentration used in the pretreatment results in more weight loss after the enzyme incubation and a shorter time window for enzymatic incubation to reach the same level of shrinkage resistance. Increasing the peroxide concentration results therefore in a higher level of protein modification which, in turn, leads to a substrate which is more sensitive for proteolytic hydrolysis. High peroxide concentrations ( $9 \mathrm{~g} / \mathrm{l}$ and beyond) in combination with enzyme incubation times which are preferred in practice for easy handling of batch

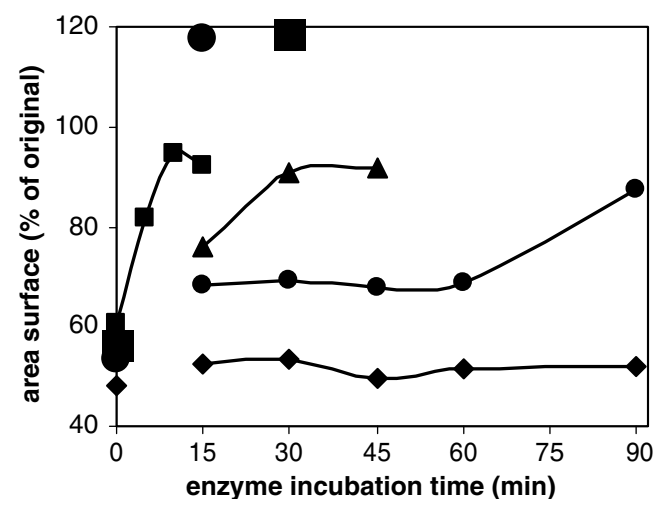

Fig. 2 Impact of peroxide concentration in the pretreatment on shrinkage behavior of knitted wool fabric after 3 wash cycles after subsequent enzyme incubation. Pretreatment time used is 15 min. Abbreviations: 0 ; 3 ; $\boldsymbol{\Delta}$ 6; enlarged $\square$ 9; 12 ; and enlarged $\bigcirc 15 \mathrm{~g}$ peroxide/l 


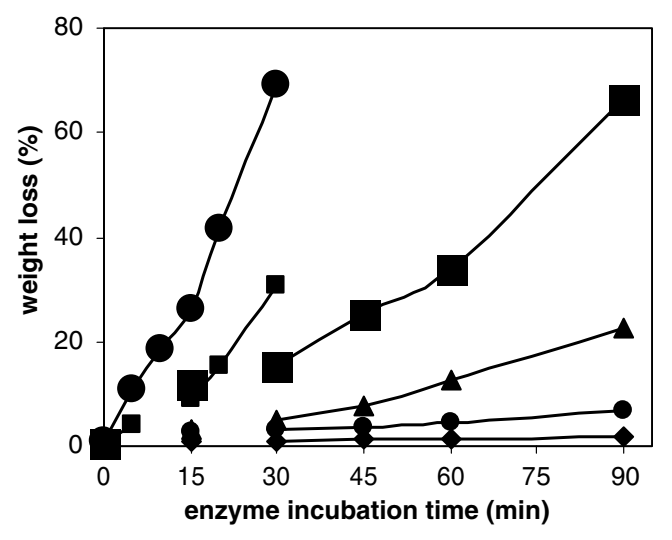

Fig. 3 Impact of peroxide concentration in the pretreatment on weight loss of knitted wool fabric after subsequent enzyme incubation. Pretreatment time used is $15 \mathrm{~min}$. Abbreviations: see legend of Fig. 2

processes (30 min or beyond) leads to weight losses of $15 \%$ and beyond. Since weight losses far beyond $4-5 \%$ are not commercial attractive, it can be concluded that the peroxide concentration to be used in the pretreatment should be $6 \mathrm{~g}$ of $35 \%$ peroxide solution/l or below by preference.

The impact of peroxide concentration has been studied in more detail to determine the more optimal concentration dosage to apply. This optimization has been done in combination with different enzyme concentrations. The results of five sets of parameters are shown in Fig. 4. It is shown that, using the right level of enzyme dosage and time frame, even a peroxide concentration of $0.5 \mathrm{~g} / \mathrm{l}$ is sufficient for effective protein modification at the outer surface of wool fibers resulting in maintaining the full size of fabric after three wash cycles.

In general it can be stated that in a situation of a lower level of protein modification (lower peroxide concentration used), there is a requirement for a longer enzyme incubation time or higher enzyme dosage to reach full shrink resistance. There are four sets of parameters which results to full shrink resistance upon application. Although these sets all lead to full shrink resistance, the measured tensile strength losses are different (Table 2). It can be stated that per level of protein modification (peroxide concentration used) a longer enzyme incubation time leads to enhanced tensile strength losses. This can be understood by

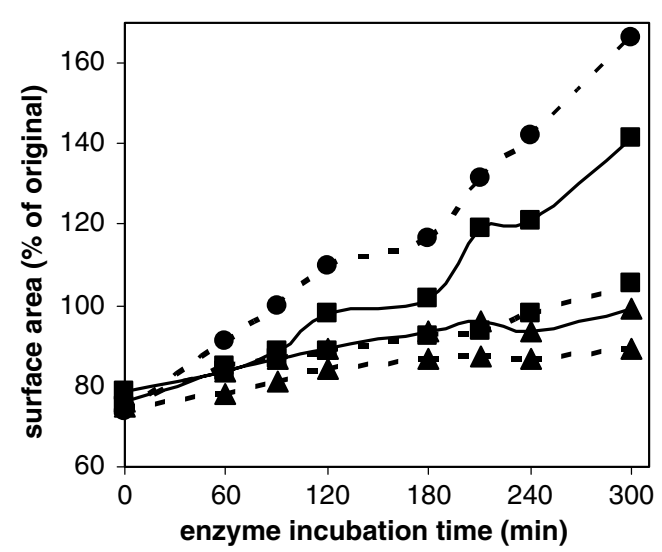

Fig. 4 Impact of different parameter combinations (peroxide concentration in the pretreatment and enzyme concentration) on shrinkage behavior of knitted wool fabric after three wash cycles. Abbreviations: $\boldsymbol{\Delta} 1 \mathrm{~g} \mathrm{H}_{2} \mathrm{O}_{2} / \mathrm{l}$ and $0.15 \mathrm{~g}$ enzyme/l; $\boldsymbol{\Delta}$ with dotted line: $0.5 \mathrm{~g} \mathrm{H}_{2} \mathrm{O}_{2} / \mathrm{l}$ and $0.15 \mathrm{~g}$ enzyme/l; $\mathbf{m}: 1 \mathrm{~g} \mathrm{H}_{2} \mathrm{O}_{2} / \mathrm{l}$ and $0.45 \mathrm{~g}$ enzyme/l; $\mathbf{\square}$ with dotted line: $0.5 \mathrm{~g} \mathrm{H}_{2} \mathrm{O}_{2} / 1$ and $0.9 \mathrm{~g}$ enzyme/1; with dotted line: $0.5 \mathrm{~g} \mathrm{H}_{2} \mathrm{O}_{2} / 1$ and $0.45 \mathrm{~g}$ enzyme/1

Table 2 Tensile strength and weight losses obtained using different sets of process parameters which all lead to full shrink resistance of wool knitted fabric

\begin{tabular}{lllll}
\hline $\begin{array}{l}\text { Peroxide } \\
\text { conc. } \\
(\mathrm{g} / \mathrm{l})\end{array}$ & $\begin{array}{l}\text { Enzyme } \\
\text { conc. } \\
(\mathrm{g} / \mathrm{l})\end{array}$ & $\begin{array}{l}\text { Enz. } \\
\text { Incub. } \\
\text { time }(\mathrm{min})\end{array}$ & $\begin{array}{l}\text { Tensile } \\
\text { strength } \\
\text { loss }(\%)\end{array}$ & $\begin{array}{l}\text { Weight } \\
\text { loss }(\%)\end{array}$ \\
\hline 0.5 & 0.45 & 240 & 56.1 & 7.4 \\
0.5 & 0.9 & 90 & 33.3 & 5.9 \\
1.0 & 0.15 & 300 & 22.5 & 5.9 \\
1.0 & 0.45 & 120 & 17.9 & 7.3 \\
\hline
\end{tabular}

the fact that prolonged enzyme incubation time leads to more internal enzyme diffusion and therefore degradation of cortex cell protein. Full shrink resistance and minimal tensile strength losses are obtained using $1 \mathrm{~g}$ peroxide/l. The higher tensile strength losses at $0.5 \mathrm{~g}$ peroxide/l can be explained by the required combination of a relative high enzyme dosage and long incubation time.

\section{Conclusions}

Enzyme technology can be used to produce wool with full shrink resistance and thus to make it 
possible to wash wool fabrics in household wash machines. However, without particular precautions this technology will result also in substantial loss in both weight and tensile strength. The results provided in this paper show that peroxide pretreatment in the presence of high concentrations of salt will modify specifically the outer surface protein layer of wool fiber and make the fiber susceptible for proteolytic hydrolysis. This pretreatment results not only in full shrink resistance but also in a reduction of tensile strength loss in comparison with the treatment without using high salt concentrations. This process could be commercial attractive since there is no severe environmental issue (contamination of wastewater with absorbable organic chlorides) as in the Chlorine-Hercosett process which is often used today. In addition, the characteristic handle of natural wool fiber will be maintained since no polymer resin is applied which is responsible for a more synthetic handle.

Acknowledgment The European Community is acknowledged for supporting this work with a grant (Growth Programme; Grant GRD1-2001-40285).

\section{References}

Bishop DP, Shen J, Heine E, Hollfelder B (1998) The use of proteolytic enzymes to reduce wool fibre stiffness and prickle. J Textile Inst 89:546-553

Bradbury JH, Rogers GE, Filshie BK (1963) The theory of shrinkproofing of wool. part V: Electron and light microscopy of wool fibers after chemical treatments. Textile Res J 33(10):617-630

Cardamone JM, Yao J, Nunez A (2004) Controlling shrinkage in wool fabrics: effective hydrogen peroxide systems. Textile Res J 74(10):887-898

Cortez J, Bonner PLR, Griffin M (2004) Application of transglutaminases in the modification of wool textiles. Enzyme Microb Technol 34:64-72

El-Sayed H, Kantouch A, Heine E, Höcker H (2001) Developing a zero-AOX shrink-resist process for wool, part !: preliminary results. Color Technol 117:234-238

Heine E, Höcker H (1995) Enzyme treatments for wool and cotton Rev Prog Col 25:57-63

Schroeder M, Schweitzer M, Lenting HBM, Gübitz GM (2004) Chemical modification of proteases for wool cuticle scale removal. Biocat Biotransf 22:299-305

Shen J, Bishop DP, Heine E, Hollfelder B (1999) Factors affecting the control of proteolytic enzyme reactions on wool. J Textile Inst 90:404-411

Simpson WS (2002) Wool: science and technology, vol 221. Woodhead Publishing Ltd, Cambridge 